- Nutritional needs and eating on a budget

- Fatigue management

- Developing coping skills.

Having a carer specific group allows the sharing of practical ideas and personal experience, as well as hospice staff being able to promote good practice, providing a forum for carers to engage with hospice services earlier for them and their families.

The three-week course is run every third month; each session lasting 90 minutes, enabling delivery to five cohorts per year. Between 2015 and 2016 the course was delivered to 70 carers.

Feedback gained following sessions suggested that the support and advice delivered was specific to their needs and delivered at the correct time to enhance confidence in their caring role when supporting their loved ones at the end of their lives. The course has been commissioned for a further 12 months by the Local Authority.

We have developed the scope of the Share and Care service to include a more informal drop-in service for carers supported by local carer support agencies known as "Carers' Retreat", supporting 85 carers in the last 12 months.

Carers play a vital role in managing issues for patients with life-limiting illnesses and the group provides practical support with this. Additionally it allows earlier access to more traditional hospice services whilst challenging stigma around the role of hospice care.

\section{P-16 CLARIFYING THE ROLE OF THE HOSPICE IN SUPPORT AND ASSESSMENT OF CARERS AND DEVELOPING BEST PRACTICE}

${ }^{1}$ Clare Hearnshaw, ${ }^{1}$ Claire Hewitt, ${ }^{2}$ Kim Barber, ${ }^{3}$ Jason Kassernoff, ${ }^{4}$ Elaine Taylor, ${ }^{5}$ Debbie Playford. ${ }^{1}$ Hospice of St Francis, Berkhamsted, UK; ${ }^{2}$ Garden House Hospice Care; ${ }^{3}$ Keech Hospice; ${ }^{4}$ Isabel Hospice; ${ }^{5}$ Rennie Grove Hospice Care

\subsection{6/bmjspcare-2016-001245.40}

In 2015, five hospice representatives across Hertfordshire and Bedfordshire met as a 'meet and finish' group to review the service that hospices and palliative care providers give to carers.

The aims of the group were to identify:

- Gaps in provision

- Types of assessment tools used

- Key learning from other services

- The need for services to collectively to reach more people.

The types of hospice support for adult family carers within the Hospice UK (2013) document "Supporting family carers: report on the evidence of how to work with and support family carers to inform the work of the Commission into the Future of Hospice Care" were used as a basis of the discussion:

- Information, training and education - moving and handling, disease process, prognosis, specific care tasks, medication, dying

- Supportive activities - Drop in sessions, self-help groups, walking or activity groups, volunteer visiting, art-making groups

- Therapeutic activities - one-to-one counselling, therapeutic support groups, drama, music or art therapy, relaxations or mindfulness classes, complementary therapies and psychotherapy.
The focus group ascertained that hospices are confidently providing therapeutic activities, however, they were less confident that hospices provide sufficient information, training and education and supportive activities for carers.

Outcome The group agreed to produce a minimum standard for specialist palliative care providers/hospices in meeting carers' needs.

Minimum standard for supporting carers by specialist palliative care providers/hospices

- Signpost those early in the trajectory to partner organisations

- Young carers

- Carer Support Needs Assessment Tool

- Moving and handling, the care towards the end of life and Caring in Confidence courses

- Leaflets and website

- Financial or benefit advice

- Supportive activities

- Therapeutic activities.

\section{P-17 THE POSITIVE IMPACT OF PROVIDING A CARER SUPPORT PROGRAMME TO INFORMAL CARERS WITHIN A HOSPICE ENVIRONMENT SETTING}

Anita Price, Christopher Lucas. Ashgate Hospice, Chesterfield, North Derbyshire

\subsection{6/bmjspcare-2016-001245.41}

Background Following a dissertation that was undertaken, research showed the biggest increase of carers over the last decade was with carers providing more complex end-of-life care (Carers UK, 2012). This led to recognising that the needs of carers were not being completely met by the service.

A project group was formed and six sessions were planned focusing on safe care, financial issues, equipment, difficult conversations, coping with dying, illness and the family, stress and anxiety, nutrition, heart failure, respiratory issues, skin care, and medication/managing symptoms.

Aim We aim to provide sessions supporting carers in their role, giving professional and topical information to empower them. Enabling them to maintain their relative at home, (Hinton, 1994, cited in Mcllfatrick, 2007) whilst gaining each others support so recognising they are not alone. Complementary therapy taster sessions were available for each visit.

Methods Carers were identified in a number of ways. To encourage positive dynamics group size was kept between eight - 10 people. Sessions ran over six weeks, supported by two volunteers and the facilitators. These were generally employees so were cost neutral. Leaflets were sourced on a variety of topics relevant to carers. Results The pilot programme was undertaken with very positive feedback from carers and staff involved. The sessions were scored on a scale of $0-10$. Average scores ranged between 8.2-9.5. This allowed sharing of information, peer support and awareness of the different support services available to them.

Conclusion Following the pilot session, the second course was planned having made adjustments based on the feedback received from carers. Equally this session evaluated positively and we now run the course twice a year. The first carers' group still met informally and have attendees of future sessions join them. 